\title{
Recurrent Artery of Heubner
}

National Cancer Institute

\section{Source}

National Cancer Institute. Recurrent Artery of Heubner. NCI Thesaurus. Code C33450.

An artery arising from the distal A1 or proximal A1 segment of the anterior cerebral artery that supplies the anteromedial caudate nucleus. 